RELACult - Revista Latino-Americana de Estudos em Cultura e Sociedade

Revista Latinoamericana de Estudios en Cultura y Sociedad | Latin American Journal of Studies in Culture and Society

V. 02, Ed. Especial, dezembro, 2016, p. 604-615 | periodicos.claec.org e-ISSN 2016/Atual: 2525-7870 | e-ISSN 2015/2016: 2447-018X

\title{
Ensino de língua espanhola na fronteira: LE ou L2?
}

\author{
Enseñanza de lengua española en la frontera: ¿LE o L2? \\ Spanish language teaching at the border: FL or L2?
}

\author{
Lic. Santiago Bretanha Freitas 1 \\ Lic. Nathalia Madeira Araujo ${ }^{2}$
}

\begin{abstract}
Resumo
O presente estudo tem por objetivo discutir, no que se refere ao ensino de língua espanhola na região fronteiriça de Jaguarão (RS/BR) e de Río Branco (CL/UY), qual a concepção de língua os professores possuem e, consequentemente, qual concepção de ensino de língua espanhola é empregada em suas práticas docentes (Língua Estrangeira, LE, ou Segunda Língua, L2); através desses dados, triangulados com nosso referencial teórico, refletimos acerca da pertinência destas concepções levando em consideração as suas epistemes e o contexto fronteiriço. Para a realização desta pesquisa, pautada em uma metodologia qualitativa, e nos pressupostos de Spinassé (2006), Baralo (1999) e Gargallo (1999), elaboramos um questionário estruturado que foi respondido por quatro professores da rede básica de ensino e por dois alunos do Curso de Licenciatura em Letras Português/Espanhol da UNIPAMPA, Câmpus Jaguarão, que atuam nas escolas jaguarenses por meio do PIBID Letras - Língua Espanhola. Levando em consideração as concepções de língua manejadas pelos sujeitos participantes da pesquisa, assim como a maneira que idealizam o ensino de espanhol na fronteira Jaguarão/Río Branco, compreendemos o ensino de língua espanhola é, majoritariamente, relacionado à perspectiva de uma L2, já que as culturas dos dois países estão em estrito e constante contato.
\end{abstract}

Palavras-chave: Ensino de Espanhol; Fronteira; Língua Estrangeira; Segunda Língua.

\section{Resumen}

El presente estudio objetiva discutir, en lo que se refiere a la enseñanza de lengua española en la región fronteriza de Yaguarón (RS/BR) y de Río Branco (CL/UY), cual la concepción de lengua los profesores poseen $y$, consecuentemente, cual la concepción de enseñanza de lengua española es empleada en sus prácticas docentes (Lengua Extranjera, LE, o Segunda Lengua, L2); por medio de eses datos, triangulados con nuestro referencial teórico, reflexionamos acerca de la pertinencia de estas concepciones teniendo en consideración sus epistemes y el contexto fronterizo. Para la realización de esta investigación, pautada en una metodología cualitativa, y en los presupuestos de Spinassé (2006), Baralo (1999) e Gargallo (1999), elaboramos una encuesta estructurada que fue contestada por cuatro profesores de la red básica de enseñanza y por dos alumnos del Curso de Licenciatura en Letras - Portugués y Español de la UNIPAMPA, campus Yaguarón, que actúan en las escuelas yaguarenses a través del PIBID Letras - Lengua Española. Contemplando las concepciones de lengua maneadas por los sujetos participantes del estudio, así como la manera como idealizan la enseñanza de español en la frontera Yaguarón/Río Branco, comprendemos la enseñanza de lengua española es, mayoritariamente, relacionada a la perspectiva de una L2, ya que las culturas de los dos países están en estricto e incesante contacto.

Palabras clave: Enseñanza de Español; Frontera; Lengua Extranjera; Segunda Lengua.

\footnotetext{
${ }^{1}$ Licenciado em Letras Português e Espanhol, mestrando em Letras; Universidade Federal de Pelotas - UFPel; Pelotas, Rio Grande do Sul, Brasil; santiagobretanha@gmail.com.

${ }^{2}$ Licenciada em Letras Português e Espanhol, mestranda em Letras; Universidade Católica de Pelotas - UCPel; Pelotas, Rio Grande do Sul, Brasil; naty_araujo@ hotmail.com.
} 


\begin{abstract}
This study aims discuss, as regards to the Spanish language teaching in the border region of Jaguarão (RS/BR) and Río Branco (CL/UY), which conception of language the teachers possess and, consequently, which Spanish language teaching concept is employed in their teaching practices (Foreign Language, FL, or Second Language, L2); through these data, compared with our theoretical framework, we reflect about the relevance of these concepts taking into account their epistemes and border context. For this research, guided by a qualitative methodology, and in the Spinassé (2006), Baralo (1999) and Gargallo (1999) postulates, we developed a structured questionnaire that was answered by four teachers of the basic school system and for two students of the Curso de Licenciatura em Letras Português/Espanhol of the UNIPAMPA, campus Jagurão, who work in jaguarenses schools through the PIBID Letras - Lingua Espanhola. Taking into account the language concepts managed by the subjects participants of the survey, as well as the way they idealize the Spanish education in the border region of Jaguarão/Rio Branco, we understand the Spanish language teaching is, mainly, related to the perspective of an L2 since the cultures of the two countries are in a strict and constant contact.
\end{abstract}

Keywords: Spanish teaching; Border; Foreign Language, Second Language.

\title{
1. Considerações iniciais
}

O município de Jaguarão/BR faz fronteira com a cidade de Río Branco/UY, desse modo percebemos, nesse contexto fronteiriço, que há grande influência das duas línguas (português/espanhol) e o contato entre duas culturas distintas. Brasileiros e uruguaios trafegam diariamente entre as duas cidades para trabalhar, comprar, passear, estudar, conviver com familiares pertencentes à outra nacionalidade. Inclusive, muitos uruguaios, por meio do processo seletivo para fronteiriços, realizam cursos de graduação e pós-graduação na Universidade Federal do Pampa (UNIPAMPA), Câmpus Jaguarão. A UNIPAMPA ${ }^{3}$ possui esse processo seletivo pois considera os espaços geográficos em que estão localizados seus campi como vetor relevante para o desenvolvimento regional.

Com base nas questões apontadas acima, atestamos o contato existente entre as populações das duas cidades, tanto por meio do comércio, quanto por meio das instituições públicas e das relações familiares. Essas questões nos levam a refletir sobre o papel e a importância que possui o ensino da língua espanhola nas escolas (municipais, estaduais e particulares) da rede básica de ensino de Jaguarão/RS, pensando no fato de que os alunos brasileiros, de uma maneira ou outra, convivem com os uruguaios. Dessa forma, torna-se difícil pensar em um ensino de língua espanhola na fronteira que desconsidere o contato (e até hibridização) entre as duas culturas.

Conforme aponta Boéssio (2010), das 19 instituições de ensino de Jaguarão/RS, no ano de 2007, somente 10 possuíam componentes curriculares acerca da língua espanhola, e, ainda, segundo a autora, as instituições que possuíam disciplinas de espanhol não abordavam

\footnotetext{
${ }^{3}$ Maiores informações podem ser encontradas no site da Universidade:

$<$ http://unipampa.edu.br/portal/fronteiricos>.
} 
os conteúdos gramaticais de uma maneira contextualizada, ou seja, considerando o contexto no qual está inserida a comunidade escolar.

Pensando na relevância que possui o ensino do espanhol em Jaguarão/RS, O presente estudo tem por objetivo discutir, no que se refere ao ensino de língua espanhola na região fronteiriça de Jaguarão (RS/BR) e de Río Branco (CL/UY), qual a concepção de língua os professores possuem e, consequentemente, qual concepção de ensino de língua espanhola é empregada em suas práticas docentes (Língua Estrangeira, LE, ou Segunda Língua, L2); através desses dados, triangulados com nosso referencial teórico, refletimos acerca da pertinência destas concepções levando em consideração as suas epistemes e o contexto fronteiriço.

Para a realização desta pesquisa, pautada em uma metodologia qualitativa, e nos pressupostos de Spinassé (2006), Baralo (1999) e Gargallo (1999), elaboramos um questionário estruturado que foi respondido por quatro professores da rede básica de ensino e por dois alunos do Curso de Licenciatura em Letras Português/Espanhol da UNIPAMPA, Câmpus Jaguarão, que atuam nas escolas jaguarenses por meio do PIBID Letras - Língua Espanhola.

\section{A pesquisa}

\subsection{Metodologia}

De acordo com Leffa (2005, p. 203), o ensino de uma língua estrangeira pode ser considerado como um problema político ou metodológico. O problema metodológico se dá quando vemos o ensino a partir do ponto de vista da sala de aula, já o problema político se instaura quando nos preocupamos, por exemplo, com a língua estrangeira que os alunos de uma determinada comunidade devem estudar.

Considerando que o problema político já está imbricado quando tratamos do ensino de espanhol em uma região de fronteira, enfatizamos que nos debruçaremos especificadamente sobre o problema metodológico. Nesse ínterim, damos enfoque a qual concepção de ensino de espanhol os professores entrevistados possuem e, consequentemente, qual a concepção de língua espanhola está sendo empregada por professores da educação básica e, da pertinência destas concepções levando em consideração as suas epistemes e o contexto fronteiriço.

A respeito da metodologia, enfatizamos que o presente trabalho é qualitativo, pois buscamos interpretar as respostas obtidas por meio da aplicação de questionários (APÊNDICE 1) e através de reflexões teóricas. Ludke e André (1986) comentam que a 
pesquisa qualitativa permite ao pesquisador participar de forma ativa no contexto de investigação, desempenhando papel relevante, e até mesmo fundamental, na coleta dos dados.

Ainda com base nessas autoras, a análise dos dados tende a seguir um processo indutivo e durante ela buscamos valorizar os significados que as pessoas atribuem às coisas, isto é, o modo como os informantes encaram as questões que lhe estão sendo colocadas. (LUDKE; ANDRÉ, 1986).

Uma das características fundamentais para entendermos a abordagem qualitativa é a de que, nela, a ênfase do estudo não está nos resultados ou produtos que serão possivelmente obtidos ao final da pesquisa, mas, sim, no processo. Entre as vantagens em utilizá-la pode ser mencionado o fato de que essa metodologia possibilita uma compreensão de um tema de uma maneira mais ampla, tendo como aporte o contexto onde o fenômeno ocorre.

\subsection{Fundamentação teórica}

Ao pensarmos no termo língua estrangeira (LE) remetemos a uma língua que é estudada pelo aprendiz, mas que está longe do seu alcance; seu uso se dá em ambientes formais de aprendizagem ou por imersão no país falante do idioma. Conforme Spinassé (2006, p. 6), “[n]o processo de aprendizado de uma LE não se estabelece um contato tão grande ou tão intenso com a mesma. A grande diferença é que a LE não serve necessariamente à comunicação e, a partir disso, não é fundamental para a Integração".

Desse modo, quando os alunos estudam uma determinada LE, ao sair na rua, eles não encontrarão falantes utilizando a língua (salvo alguma exceção); inclusive os alunos não precisarão falar no idioma estudado para poder comunicar e estabelecer relações com os demais sujeitos. Neste caso, o input linguístico é fornecido somente por intervenção pedagógica, em contextos simulados de utilização da língua.

A ideia do input é a terceira hipótese de Krashen; segundo ela o professor deve oferecer aos alunos o input (insumos - exposição à língua alvo) adequado para proporcionar um bom espaço de aprendizagem aos estudantes. Ainda, para que os alunos passem de um estado atual de língua para um mais avançado, é necessário oferecer o input+1, isto é, o input deve sempre conter informação linguística nova.

Ao contrário do termo LE, o termo Segunda Língua (L2) faz menção ao idioma que circula e possui uma função no contexto em que o sujeito vive. Para Spinassé (2006, p. 6), ele é " [d]iferenciado [...] do conceito de Língua Estrangeira (LE), uma Segunda Língua é uma não-primeira-língua que é adquirida sob a necessidade de comunicação e dentro de um processo de socialização". 
Assim sendo, ela é uma língua não nativa, mas que faz parte do contexto situacional; daí surge a necessidade, por parte dos falantes, de aprendê-la já que ela “[c]umpre uma função social e institucional na comunidade lingüística em que se aprende" (GARGALLO, 1999, p. 21). Quando se trata de uma L2, o aluno é constantemente exposto de forma natural a input linguístico real.

Outra hipótese formulada por Krashen, e que consideramos relevante, é a do filtro afetivo; segundo Baralo (1999, p. 61) o filtro afetivo, “[s]e trata de uma espécie de barreira que impede usar de forma adequada os dados do input aos que aprendem". Isso significa que “o aprendiz com uma motivação alta e com confiança em si mesmo terá o filtro afetivo muito baixo e se produzirá uma aquisição bem sucedida"; em contrapartida, "o aprendiz com uma motivação baixa, com pouca confiança em si mesmo, terá um filtro muito alto e receberá muito pouco input".

Dessa forma, os indivíduos com atitudes positivas em relação à língua estrangeira terão mais facilidade para aprender porque buscam mais input, quanto mais baixo o filtro afetivo do aluno, mais ele aprende. Ao contrário, os estudantes que tem o filtro afetivo elevado não aprenderão com grande efetividade. Krashen aponta que o melhor professor é aquele que oferece o input correto aos alunos, que pode tornar esse input o mais compreensível possível e em condições de baixa ansiedade.

\subsection{Os sujeitos}

Os questionários foram respondidos no período de outubro a dezembro de 2015. Seis sujeitos com idades de vinte e um a trinta e dois anos participaram da investigação. Sendo eles, quatro professoras com graduação em licenciatura em Letras Português/Espanhol e respectivas literaturas. Dessas quatro, uma realiza Mestrado Profissional em ensino de Línguas pela UNIPAMPA, Câmpus Bagé, e outras duas possuem Especialização no Ensino de Línguas pela UNIPAMPA, Câmpus Jaguarão.

Participaram da pesquisa, ainda, um aluno do curso de Licenciatura em Letras Português/Espanhol da Unipampa, campus Jaguarão, que atua nas escolas por meio do Programa Institucional de Bolsas de Iniciação à Docência (PIBID) Letras - Língua Espanhola, e uma aluna do curso de Licenciatura em Letras Português/Espanhol UNIPAMPA, Câmpus Jaguarão, que leciona nas escolas por meio do PIBID Letras - Língua Espanhola.

Todos os sujeitos que responderam ao questionário atuam na disciplina de língua espanhola em escolas particulares, municipais, estaduais, da cidade de Jaguarão/RS. Dos seis 
participantes apenas uma leciona em cursos pré-vestibulares, cursos preparatórios para concursos e na Educação de Jovens e Adultos. As quatro primeiras perguntas que compõem o questionário nos deram o subsídio para coletar os dados dos sujeitos.

\section{Interpretação das respostas obtidas e algumas considerações}

Em resposta à pergunta de número cinco "Levando em consideração o contexto de fronteira no qual vivemos, você acredita que o espanhol é uma língua estrangeira (LE), que é aquela que está longe ou uma segunda língua (L2), justifique sua resposta” os professores W, $\mathrm{B}, \mathrm{Z}$ e H, manifestaram-se considerando o espanhol nessa região de uma fronteira como uma L2, ainda conforme o sujeito z: Acredito que neste contexto de fronteira o espanhol é uma segunda língua ou língua adicional, porque há interação e contato com a língua do outro. Por momento, esse outro se confunde conosco mesmo. Portanto, há proximidade nas diferenças.

Já para o sujeito H: Acredito que nesse contexto ela se torne necessária, sendo que direta ou indiretamente temos contato com essa língua diariamente, desde ambientes mais informais como em ambientes formais. As respostas desses dois sujeitos que trouxemos como exemplo, bem como o posicionamento quase que unânime dos demais a essa pergunta, nos levam a perceber que ensinar o espanhol nessa região é ensinar uma língua que faz parte da rotina dos estudantes, é ensinar um idioma que está na escola, na roda de amigos, na família, no comércio. Isto é, consideravelmente, o espanhol, neste contexto, é uma L2, pois as trocas e a convivência entre os dois povos impossibilitam que a consideremos com uma LE.

Em resposta à questão número seis "Levando em conta o contexto de fronteira os alunos: 'gostam do espanhol', 'não gostam', 'alguns gostam e outros não gostam', 'possuem mais facilidade para adquirir/aprender o idioma"" os seis professores participantes da pesquisa responderam afirmando que ocorre um grande desinteresse pelo estudo da língua por parte dos alunos.

Algumas justificativas dos professores para esse desinteresse foram:

A) O estigma de que o espanhol é uma língua muito fácil. Muitos estudantes devido às semelhanças entre o português e o espanhol acreditam que o espanhol é muito fácil e na hora de aprender as regras veem que tal semelhança, entre os idiomas, muitas vezes faz com que o processo de aprendizagem se torne mais difícil, principalmente no que concerne à interferência de uma língua na outra no processo de aprendizagem. Por mais que muitos dos estudantes de Jaguarão/RS falem o espanhol, na hora utilizar a língua de uma maneira mais formal, como na escrita, encontram dificuldades e se frustram. 
B) Falta de perspectiva pela desvalorização do idioma e de seus falantes. Percebe-se que existe, por parte dos habitantes de Jaguarão/RS, certa resistência ao reconhecer a cultura uruguaia e a importância que o espanhol possui para a cultura local e regional; essa desvalorização reflete na escola, pois muitos estudantes não veem relevância ao estudar o espanhol.

C) $\mathrm{O}$ curto tempo dedicado para a disciplina. O espanhol é disciplina optativa nas escolas estaduais do município; os alunos optam pelo espanhol ou pelo inglês. Já nas escolas municipais e particulares o idioma é disciplina obrigatória. Porém, em todas as escolas, são disponibilizados apenas um ou dois períodos letivos para a língua espanhola por semana.

D) A utilização de materiais didáticos que contemplam a variedade peninsular do espanhol. Conforme resposta da professora $\mathrm{W}$, muitos professores utilizam materiais didáticos provenientes da Espanha e, consequentemente, ao lecionar em contexto de fronteira, esse professor apresenta um espanhol diferente para os estudantes. Isso faz com que os alunos, por mais que já saibam o espanhol, passem a acreditar que não sabem, pois só conhecem a variedade rio-platense.

Sobre isso Cabral (2015), argumenta que, "Os materiais didáticos adquirem suma importância nessa perspectiva, considerando que possuem grande potencial como ferramenta nos processos de ensino e aprendizagem" (p. 11). Ainda, segundo a mesma autora, "em um momento que é sabido que a grande maioria dos materiais são provenientes da Espanha, cabe ao professor de espanhol adaptar ou, se é o caso, buscar alternativas que contemplem o contexto no qual o aluno está inserido". (CABRAL, 2015, p. 11).

A partir da argumentação da autora, acreditamos que, no contexto sobre o qual falamos, cabe aos professores de língua espanhola utilizar amostras reais de língua para ensinar, apropriando-se de amostras de input real. O professor pode fazer com que materiais autênticos, como panfletos, jornais, revistas, folhetos, programas televisivos, materiais publicitários, entre outros, oriundos de Río Branco/UY, tornem-se materiais didáticos.

Acreditamos que todos esses fatores negativos, mencionados acima, possibilitam que o filtro afetivo desses alunos suba, e, quanto mais negativa a posição do aluno perante a língua estudada, menos ele aprende e menos se interessa pelo idioma. Ao ensinar a variedade peninsular, o professor está ensinando o espanhol como LE, desconsiderando a variedade rioplatense proveniente do Uruguai, o que desencadeia uma questão: como ensinar o espanhol como LE para estudantes que vivem na fronteira? Aqui voltamos às perguntas centrais desse estudo, qual concepção de língua espanhola está sendo empregada por professores da educação básica (LE ou língua L2)? Qual seria a mais pertinente levando em conta o contexto 
fronteiriço? Quatro dos sujeitos da pesquisa responderam que ensinam o idioma como L2, e levando em conta as discussões realizadas até o momento, acreditamos que essa seja a mais adequada.

Em resposta às perguntas de número oito e nove, que se referiam ao ensino da gramática, houve uma divisão de posicionamentos; alguns responderam que os estudantes não sabem a gramática da língua e que outros possuem dificuldades para aprender, ao passo que os professores $\mathrm{W}, \mathrm{Y}, \mathrm{Z}$ responderam que os alunos não possuem grandes dificuldades, já que conhecem o idioma.

E para finalizar, em resposta às perguntas de número dez e onze, que faziam referência a que tipos de atividades que poderiam ser elaboradas pelos professores para ensinar a língua espanhola, considerando o espaço fronteiriço, os sujeitos sugeriram atividades que levassem em conta o contexto, os aspectos culturais.

Nas palavras do sujeito W: Creio que as atividades devem abarcar o contexto em que está inserido - levando em consideração a cultura e a bagagem já existente dos alunos, assim como a utilização da variedade rio-platense, neste caso. Atividades orais e auditivas devem receber maior valor, pois o fluxo comercial neste contexto é forte. Tal posicionamento se assemelha a resposta do sujeito Y que argumenta que são importantes: Atividades que demonstrem o quanto estamos próximos, seja geograficamente, culturalmente, linguisticamente dos falantes do idioma espanhol.

Ambos os professores, enfatizam a necessidade de planejar aulas que partam da realidade desses estudantes, abarcando questões culturais, linguísticas, sociais, concebendo a língua espanhola com uma L2.

\section{Considerações finais}

Tomando por referência o estudo que aqui apresentamos, acreditamos haver traçado uma investigação breve, porém de relevância regional visto que, através dela, alçamos mãos a dados e reflexões basilares para que se pense o ensino de língua espanhola na fronteira Jaguarão/Río Branco; salientamos o reconhecimento do espanhol enquanto L2 e a compreensão das culturas em contato no espaço hibrido fronteiriço.

Levando em consideração as concepções dos sujeitos participantes da pesquisa sobre o que é ensinar espanhol na fronteira, qual terminologia de língua eles usam, e as definições de LE e L2 propostas por Spinassé (2006), acreditamos que na região a qual se insere essa pesquisa a língua espanhola pode ser compreendida como uma L2, já que os indivíduos das duas nacionalidades convivem diariamente. 
RELACult - Revista Latino-Americana de Estudos em Cultura e Sociedade

Revista Latinoamericana de Estudios en Cultura y Sociedad | Latin American Journal of Studies in Culture and Society V. 02, Ed. Especial, dezembro, 2016, p. 604-615 | periodicos.claec.org e-ISSN 2016/Atual: 2525-7870 | e-ISSN 2015/2016: 2447-018X

A partir disso, ainda, defendemos um ensino de espanhol que contemple a variedade rio-platense do idioma, que é aquela que está próxima dos estudantes de Jaguarão/RS, e acreditamos no ensino de L2 baseado na utilização de materiais autênticos, o que faz com que os professores busquem por alternativas que deem conta do contexto no qual estão inseridos esses estudantes.

\section{Referências}

BARALO, M. La adquisición del español como lengua extranjera. Madrid: Arco/ Libros, 1999

BOÉSSIO, C. P. D. Práticas docentes com o ensino da língua espanhola nas séries

iniciais. 245 f. Tese (Doutorado em educação), Faculdade de Educação, Universidade Federal de Pelotas, Pelotas, 2010.

CABRAL, C. D. La cultura de frontera a los ojos de educadores fronterizos. 2015. $47 \mathrm{f}$. Trabalho de Conclusão de Curso (Licenciatura em Letras Português/Espanhol), Universidade Federal do Pampa. Jaguarão, 2015.

GARGALLO, I. S. Lingüística aplicada a La enseñanza: aprendizaje del español como lengua extranjera. Madrid: Arco libros, 1999.

LEFFA, V. J. O professor de línguas estrangeiras: do corpo mole ao corpo dócil. In: FREIRE, M. M.; ABRAHÃO, M. H. V.; BARCELOS, A. M. F. (Org.). Lingüística Aplicada e contemporaneidade. São Paulo: ALAB/Pontes, 2005, p. 203-218.

LÜDKE, M.; ANDRÉ, M. E. D. A. Pesquisa em educação: abordagens qualitativas. São Paulo: EPU, 1986.

SPINASSÉ, K. P. Os conceitos de língua materna, segunda língua e língua estrangeira e os falantes de línguas alóctones minoritárias no sul do Brasil. In: Revista contingentia, v. 1, n. 1, nov. 2006, p.01-10. 
Apêndice 1: Questionário Estruturado

\section{APÊNDICE}

$\left.1^{\circ}\right)$ Você é professor:

( ) já graduado ( ) em graduação

( ) Outros. Quais?

$\mathbf{2}^{\mathbf{0}}$ ) Seu ramo de atuação é:

( ) escolas estaduais ( ) escolas municipais ( ) escolas particulares

( ) Outros? Quais

$3^{\circ}$ ) Você é professor:

( ) contratado ( ) concursado

( ) que atua no Programa Institucional de Bolsas de Iniciação à Docência (PIBID)

( ) que atua em outros projetos; tais como

$4^{\circ}$ ) Quantos anos você possui de experiência no ensino de língua espanhola?

$5^{\circ}$ ) Levando em consideração o contexto de fronteira no qual vivemos, você acredita que o espanhol é:

( ) uma língua estrangeira (LE), que é aquela que está longe.

( ) uma segunda língua (L2).

Justifique sua resposta:

$6^{\circ}$ ) Levando em conta o contexto de fronteira os alunos: 
RELACult - Revista Latino-Americana de Estudos em Cultura e Sociedade

Revista Latinoamericana de Estudios en Cultura y Sociedad | Latin American Journal of Studies in Culture and Society V. 02, Ed. Especial, dezembro, 2016, p. 604-615 | periodicos.claec.org e-ISSN 2016/Atual: 2525-7870 | e-ISSN 2015/2016: 2447-018X

a) ( ) gostam do espanhol ( ) não gostam do espanhol ( ) alguns gostam e outros não gostam

b) ( ) possuem mais facilidade para adquirir/aprender o idioma?

( ) $\operatorname{sim}$ ( ) não. Por quê?

c) Em sua opinião, o desinteresse pelo estudo da língua espanhola por parte dos alunos ocorre por quê?

$7^{\circ}$ ) Em sua opinião, nas aulas de língua espanhola o professor deve enfatizar o desenvolvimento:

( ) da escrita

( ) da fala

( ) da audição

( ) da leitura $\quad$ ( ) de ambas aptidões

$\mathbf{8}^{\mathbf{o}}$ ) Em relação ao conteúdo gramatical, todos os alunos dominam a gramática da língua espanhola?

( ) $\operatorname{sim}($ ) não

$\mathbf{9}^{\mathbf{0}}$ ) Você acredita que a gramática também deve ser ensinada. Por quê?

$\mathbf{1 0}^{\circ}$ ) Levando em conta o contexto de fronteira, que tipos de atividades poderiam ser empregadas pelos professores de forma a motivar os alunos perante o estudo da língua espanhola? 
$\mathbf{1 1}^{\circ}$ ) Mesmo enfocando o conteúdo gramatical, o professor pode elaborar atividades diferentes utilizando amostras reais de uso da língua como rádio uruguaia, jornal uruguaio, folhetos de lojas, entre outros.
( ) $\operatorname{sim}$
( ) não

Por quê? 